\title{
Prevalence of Leptospirosis Among Patients Attending Renal and General Outpatient Clinics in Mulago Hospital, Kampala, Uganda
}

Rogers Wambi ( $\sim$ rogerwambi@gmail.com )

Mulago Hospital

William Worodria

Mulago Hospital

James Muleme

Makerere University

Siya Aggrey

Makerere University

Lawrence Mugisha

Makerere University

\section{Research Article}

Keywords: Prevalence of leptospirosis, renal and general outpatient clinics, Microscopic Agglutination Test (MAT)

Posted Date: August 4th, 2021

DOI: https://doi.org/10.21203/rs.3.rs-745094/v1

License: (c) (1) This work is licensed under a Creative Commons Attribution 4.0 International License. Read Full License 


\section{Abstract}

In this study we sought to establish the prevalence and associated factors of Leptospirosis among renal patients and general outpatients attending Mulago National Referral Hospital, Uganda. This crosssectional study recruited and collected blood samples from a total of 254 patients attending Mulago hospital from July to October 2018. Additionally, the semi-structured questionnaires were administered to enrolled patients to collect data on socio-demographics and occupational practices that may be risks of getting infected with Leptospirosis. The blood samples were analyzed using the standard Microscopic Agglutination Test (MAT) with a panel of 14 Leptospira-serovars belonging to 10 serogroups. We identified 12 seropositivity of Hebdomadis, Hebdomadis (L.borgapetersenii serovar Nona), Icterohaemorrhagiae (L.interrogans Serovar Icterohaemorrhagiae, Canicola (L. interrogans serovarCanicola), Djasiman (L. interrogansserovarDjasiman), Pomona (L. interrogans serovar Pomona) and Ballum (L. borgpetersenii serovar Kenya). The overall prevalence of leptospirosis in examined samples was $4.7 \%(\mathrm{Cl}=2.6-8.3, \mathrm{P}<0.05)$ among patients attending Renal and General Outpatient clinics in Mulago hospital. The participants who reported with fever were 15.4 times more likely to be diagnosed with leptospirosis. The study reveals that leptospirosis may be among the causative agents among renal patients and should be included among the differential diagnostic list to consider for further testing and diagnosis.

\section{Introduction}

Leptospirosis is a zoonotic bacterial infection caused by spirochetes, which belong to the genus Leptospira. It is the most widespread zoonosis in the world and is considered a global public health challenge [1]. Studies conducted globally have reported both domestic animals such as dogs and wild animals such as rodents being reservoirs for Leptospira species [2,3]. Many of such infected animals shed lepto-spirochetes (being distinguished by the helical shape of the bacteria) through their urine into the environment in water and soil which accounts for the wide geographical distribution of the disease worldwide [4]. In addition to their distribution, spirochetes have the ability to withstand harsh environmental conditions such as $\mathrm{pH}$ and temperature [5] viable for new host infection.

Leptospirosis has the ability to invade a wide array of hosts making it hard to control and prevent thus a public health threat [4] especially in developing countries where the infrastructure present are not commensurate to this need. Additionally, the wide distribution of dogs in Uganda [6, 7] complicates the control and prevention of Leptospirosis especially its spread to the human population. Besides animals, ecosystem changes including population pressure, habitat extermination and climatic variations have fueled the spread of leptospirosis globally.

Globally, estimated 1.03 million cases and 58,900 deaths occur annually as revealed by Leptospirosis Epidemiology Reference Group (LERG)[8]. Additionally, a study conducted from 11 hospital based sites in Africa among acute febrile patients and revealed a (2.3-19.8)\% prevalence [9]. Studies conducted among dogs and humans in Uganda reported prevalence rates of $27 \%$ and $35 \%$ using the Microscopic 
Agglutination(MAT) test $[10,11]$ respectively. Despite the prevalence of leptospirosis, the self-limiting in the majority population conceals its severity [12].

Studies have shown that severity of the disease has been associated with multi-organ involvement of pulmonary haemorrhage syndrome and acute kidney injury, which justifies the current study's focus on both the renal and general outpatient individuals [13]. Furthermore, most febrile cases are misdiagnosed especially in low-resource settings where the majority are diagnosed and treated for malaria exclusively $[14,15,16,17]$. For example, a study done in Kabarole District of Uganda among febrile patients found $38 \%$ being malaria cases and the other $62 \%$ patients having unexplained causes of fever [18]. Such undiagnosed cases may lead to late detection and complications associated with Leptospirosis infections progressing into complicated stages of multi-organ involvement such as kidney and lung dysfunction $[19,20]$. Therefore, this study sought to establish the prevalence of leptospirosis among patients attending renal and general outpatient units in Mulago National Referral Hospital, Uganda.

\section{Materials And Methods}

This was across sectional study conducted in the renal and general outpatients' units of Mulago National Referral Hospital, Kampala, Uganda. The Hospital receives referred patients from all districts of the country with official capacity of 1,790 beds, although it often houses over 3,000 patients. The hospital has 2,057 health care professionals (Africa Health Workforce Observatory, 2009). The study population comprised of both female and male patients attending renal and general outpatient units in Mulago hospital during the study period. The study participants were enrolled purposively until the required sample size of 254 was achieved. And they were of age categories of young, youth, adults and elderly. All processes involved in this study were executed in accordance with the guidelines and regulations stated in the ethical approval document (reference number -MHREC 1347).

\section{Data collection tools and methods}

The questionnaire was administered to all the 254 participants in the renal and general out patient's units while waiting to be examined by the clinicians. This was purposely to obtain (address, gender and age), socioeconomic data (occupation and education level) and information on (contact with rodents, flooding of household and surroundings and water source) (details refer to appendix II). Occupation was grouped into two categories namely Professionals (those with a minimum of certificates academic qualification) and Non-professionals (those without a minimum of a certificate academic qualification).

The research also used patient's information of body temperature, physical examination and history of previous treatment clerked by the clinician and filled special laboratory request form (details refer to appendix I). This focused on answering the associated factors with the prevalence of leptospirosis.

Blood samples were collected from participants and allowed to stand for between 30 and 60 minutes to clot, then centrifuged for 5 minutes at a speed of $3000 \mathrm{rpm}$ centrifugal force to separate the serum. The 
Serum was placed in aliquots in the cryovials, packed in the cool box and transported to Central Diagnostic Laboratory found in College of Veterinary and Biosecurity, Makerere University for analysis. During testing at the central Diagnostic Laboratory, the standard microscopic agglutination test (MAT) with a panel of 14 Leptospira serovars belonging to 10 serogroups. These included: Autumnalis represented by (L. interrogans serovar Autumnalis) Ballum (L. borgpetersenii serovar Kenya), Canicola ( $L$. interrogans serovarCanicola), Tarassovi (L.borgapetersenii serovar Tarassovi) Hebdomadis (L.borgapetersenii serovar Nona),Pomona (L. interrogansserovar Pomona), shermani (L.santarosai serovar Shermani), Djasiman (L. interrogans serovar Djasiman), Pyrogenes (L.borgapetersenii serovar Nigeria), Sejroe (L.borgapetersenii serovar Sejroe) Icterohaemorrhagiae (L.kirschneri serovar Sokoline), Icterohaemorrhagiae (L.interrogans Serovar Icterohaemorrhagiae, Copenhageni).

Plate plan was drawn for each run and samples were diluted in the ratio of 1:50 by adding $100 \mathrm{ul}$ of test serum in $4.9 \mathrm{mls}$ of saline for step one screening. Then two-fold dilutions of each sample up to 1:1600 for step two titration. And $100 \mathrm{ul}$ of controls were added to each well as indicated on the Titration plate plan. Finally, $100 \mathrm{ul}$ of the test serovars(s) to each of the appropriate wells. The plate setup shaking was for 30 seconds at $50 \mathrm{rpm}$ on a mikrotitre plate shaker (Orbit P4, Labnet International Inc. NJ-USA). The preparation was incubated at $29^{\circ} \mathrm{C}$ for 2.5 hours and the examined using a stereo microscope at high light intensity for agglutination. And only sera with a titre of $\geq 100$ was interpreted as positive.

\section{Data analysis}

Data from the questionnaire was first entered in the research laboratory registers and then later double entered into the computer using EPI DATA package 2.1, and then subsequently exported to a statistical software programme R version 3.5.2 (2018-12-20) for analysis. The frequencies and proportions were determined. $P$ values of below 0.05 were considered significant and a confidence interval of $95 \%$ was used. Multivariate logistic regression models were done to show the association between independent variables and the dependent variable (leptospirosis). Odds ratios were calculated showing predictive risk factors. Data were summarized in tables and graphs.

\section{Ethics consideration}

This study was approved by Mulago National Referral Hospital Research and Ethics Committee (approval number -MHREC 1347). In addition, written informed consent was sought from all the study participants and those that did not consent were allowed to access health services and were excluded from the study. At every subsequent stage of handling samples, every effort was made to ensure that the patient's identity is protected from third parties: "the use of study numbers instead of the actual patients' names was adhered to. In circumstances were the participants involved minors (below 18 years old), written informed consent was sought from the parent or guardian that escorted them to the health facility. 


\section{Results}

\section{Socio-demographics and prevalence of Leptospirosis}

A total of 254 patients comprising of 126 (49.6\%) males and 128 (50.2\%) females were enrolled for sample collection and interviews. Their age groups varied between 0-35 (49.2\%) and 36-87 (50.8\%) years. The majority of the patients $149(58.7 \%)$ had attained post-primary education. A greater proportion of $238(93.7 \%)$ of the study patients were coming from the central region of Uganda with only few $6(2.4 \%)$ coming from the eastern part of the country. Most participants $162(63.8 \%)$ were found to be in nonprofessional occupations compared to their counterparts (see table 1). Additionally, a proportion of $131(51.6 \%)$ of the respondents had a fever with an average body temperature of $37.3 \pm 1.1^{\circ} \mathrm{C}$. Clinical history notes of the examined patients revealed that patients had suffered from malaria (22.8\%), the flue $(14 \%)$, and brucellosis (3.5\%). Further, $32(12.6 \%)$ of the patients reported to had used antibiotics in the last one month to treat infections. Antibiotics commonly used were Amoxicillin $50 \%$ followed by ampicillin, ceftriaxone and gentamycin at $9 \%$.

In this study, we report the overall prevalence of leptospirosis of $4.7 \%(\mathrm{Cl}=2.6-8.3, \mathrm{P}<0.05)$ amongst patients attending Renal and General Outpatient units in Mulago National Referral Hospital. Leptospirosis was found to be more prevalent (5.6\%) among the patients of age group ranging from 36-87 years. The males had the highest $(5.6 \%)(\mathrm{Cl}=2.5$ - 11.5) prevalence compared to their females' counterparts $(3.9 \%)$. Individuals who had attained primary and below level education had the highest prevalence $(6.6 \%)$ compared to those with at least secondary school level education. Meanwhile, professionals had the highest prevalence (5.4\%) compared to nonprofessionals (See Table 1).

Table 1

Showing Leptospirosis prevalence characterization by socio-demographics 


\begin{tabular}{|c|c|c|c|}
\hline Variable & Level & $\begin{array}{l}\text { Frequency } \\
(\mathrm{N}=254)\end{array}$ & $\begin{array}{l}\text { Prevalence (\%) (95\% } \\
\mathrm{Cl})\end{array}$ \\
\hline \multirow[t]{2}{*}{ Age } & $0-35$ & 125 & $3.9(1.4-9.3)$ \\
\hline & $36-87$ & 129 & $5.6(2.5-11.6)$ \\
\hline \multirow[t]{2}{*}{ Sex } & Female & 128 & $3.9(1.4-9.3)$ \\
\hline & Male & 126 & $5.6(2.5-11.5)$ \\
\hline \multirow[t]{2}{*}{ Education level } & Primary \& below & 105 & $6.6(2.9-13.7)$ \\
\hline & $\begin{array}{l}\text { Secondary\& } \\
\text { above }\end{array}$ & 149 & $3.4(1.28 .1)$ \\
\hline \multirow[t]{3}{*}{ Address } & Central & 238 & $5.0(2.7-8.9)$ \\
\hline & Eastern & 6 & $0(0.0-4.8)$ \\
\hline & Western & 10 & $0(0.0-3.4)$ \\
\hline \multirow[t]{2}{*}{ Occupation } & nonprofessional & 162 & $4.3(1.9-9.0)$ \\
\hline & Professional & 92 & $5.4(2.0-12.8)$ \\
\hline \multirow{2}{*}{$\begin{array}{l}\text { Contact with rodents and wild } \\
\text { animals }\end{array}$} & Yes & 77 & $1.3(0.1-8.0)$ \\
\hline & No & 177 & $6.2(3.3-11.1)$ \\
\hline \multirow{2}{*}{$\begin{array}{l}\text { Type of Domestic animals kept } \\
\text { Cattle }\end{array}$} & Yes & 63 & $1.6(0.0-9.7)$ \\
\hline & No & 191 & $5.7(3.0-10.3)$ \\
\hline \multirow[t]{2}{*}{ Sheep } & Yes & 16 & $0(0.0-24.0)$ \\
\hline & No & 238 & $5.0(2.7-8.9$ \\
\hline \multirow[t]{2}{*}{ Goats } & Yes & 72 & $1.4(0.0-8.5)$ \\
\hline & No & 182 & $6.0(3.2-10.8)$ \\
\hline \multirow[t]{2}{*}{ Pigs } & Yes & 33 & $6.0(1.0-21.6)$ \\
\hline & No & 221 & $4.5(2.3-8.4)$ \\
\hline \multirow[t]{2}{*}{ Wildlife } & Yes & 7 & $14.2(0.7-57.9)$ \\
\hline & No & 247 & $4.4(2.3-8.0)$ \\
\hline \multirow[t]{2}{*}{ Antibiotic use } & Yes & 32 & $0(0.0-5.1)$ \\
\hline & No & 222 & $6.0(2.7-.9 .2)$ \\
\hline Abdominal pain & Yes & 131 & 4.4 (1.2 9.1) \\
\hline
\end{tabular}




\begin{tabular}{|lll|} 
Source of water & 123 & $3.9(1.4-10.3)$ \\
\hline Tap & 160 & $3.7(1.5-8.3)$ \\
\hline Well & 51 & $5.9(1.5-17.2)$ \\
\hline Lake & 2 & $0(0.0-80.2)$ \\
\hline River & 1 & $0(0.0-94.5)$ \\
\hline Bore hole & 40 & $7.5(1.9-21.5)$
\end{tabular}

Professionals=all participants with a minimum of certificates in relation to their occupation.

Non-professionals=participants without a minimum of a certificate in relation to their occupation.

Age group 0 - 35= young and youth

Age group $36-78+=$ old and elderly

Results from this study revealed twelve (12) seropositive cases of Leptospira with titres $\geq 100$. The total of 12 seropositivity with leptospira serovars was observed among both Renal and General outpatient units of Mulago National referral Hospital. Djasiman and Canicola were more prevalent in both patient categories with titers of $\geq 200$ and $\geq 400$ (See Figure 1). In the Renal Unit, one (1) individual was positive for both Djasiman and Hebdomadis Leptospira serovars. Similarly, in the General outpatient unit, another individual was positives for Icterhaemorhagic strain RGA and Canicola Leptospira serovars

\section{Factors associated with Leptospirosis among study participants}

Bivariate analysis results revealed that individuals who had fever pain during the sample collection were 15.4 times more likely to have leptospirosis compared to those who never had had fever $\mathrm{OR}(95 \% \mathrm{Cl})$, 15.4(1.17- 150.57). The participants who had not used antibiotics in the past month were 2.2 times to be diagnosed with leptospirosis. In the bivariate analysis, participants with the signs of fever were 1.3 times more likely to be diagnosed with leptospirosis. For those individuals with dehydration were found to be diagnosed with leptospirosis infection OR (95\% Cl), 0.14(1.00-1.0) (See Table 2)

Table 2

Bivariate analysis showing factors associated with Leptospirosis 


\begin{tabular}{|c|c|c|c|}
\hline Variable & Level & $\mathrm{OR}(95 \% \mathrm{Cl})$ & P-value \\
\hline \multirow[t]{2}{*}{ Age } & $0-35$ & 1 & - \\
\hline & $36-87$ & $0.68(0.172 .57)$ & 0.57 \\
\hline \multirow[t]{2}{*}{ Sex } & Female & 1 & - \\
\hline & Male & $1.44(0.38-5.94)$ & 0.57 \\
\hline \multirow[t]{2}{*}{ Education level } & Primary \& below & 1 & - \\
\hline & Secondary \& above & $0.49(0.12-1.84)$ & 0.24 \\
\hline \multirow[t]{3}{*}{ Address } & Central & 1 & - \\
\hline & Eastern & $0.49(0.12-1.84)$ & 0.24 \\
\hline & Western & $0.49(0.12-1.84)$ & 0.24 \\
\hline \multirow[t]{2}{*}{ Occupation } & nonprofessional & 1 & - \\
\hline & Professional & $1.27(0.31-4.81)$ & 0.76 \\
\hline \multirow[t]{2}{*}{ Type of Domestic animals kept Cattle } & No & 1 & - \\
\hline & Yes & $0.26(0.01-1.89)$ & 0.30 \\
\hline \multirow[t]{2}{*}{ Sheep } & No & 1 & - \\
\hline & Yes & $0(0.00-5.64)$ & 1 \\
\hline \multirow[t]{2}{*}{ Goats } & No & 1 & - \\
\hline & Yes & $0.22(0.005-1.56)$ & 0.66 \\
\hline \multirow[t]{2}{*}{ Fever } & No & 1 & - \\
\hline & Yes & $15.4(1.17-150.57)$ & $0.02 \star$ \\
\hline \multirow[t]{2}{*}{ Dehydration } & No & & - \\
\hline & Yes & $0.14(1.00-1.0)$ & $0.033^{*}$ \\
\hline \multirow[t]{2}{*}{ Antibiotic use } & Yes & 1 & - \\
\hline & No & $2.2(0.37-9.7)$ & 0.20 \\
\hline \multirow[t]{2}{*}{ Abdominal pain } & Yes & 1 & - \\
\hline & No & $1.3(0.33-5.5)$ & 0.77 \\
\hline
\end{tabular}




\section{Multivariable logistic regression analysis for the risk factors associated with Leptospirosis infection among study participants}

The patients who reported with signs of fever were 24.4 times more likely to be diagnosed with leptospirosis $(\mathrm{Cl}=2.42-267.89)$. However, those reported with dehydration to the renal and general outpatient units in Mulago National Referral hospital were ten times less likely to be diagnosed with Leptospirosis $(\mathrm{Cl}=0.01-0.69)$. Even though not statistically significant, male patients reporting to the hospital had 1.9 more chances of being diagnosed with leptospirosis compared the female counterparts (see Table 3 below).

Table 3

Multivariable logistic regression showing risk factors for Leptospirosis infection

\begin{tabular}{|llll|}
\hline Variable & Level & Adjusted OR $(95 \% \mathrm{Cl})$ & P-value \\
\hline Age & $0-35$ & 1 & - \\
\cline { 2 - 4 } & $36-87$ & $0.8(0.22-2.73)$ & 0.69 \\
\hline Sex & Female & 1 & - \\
\cline { 2 - 4 } & Male & $1.9(0.54-7.45)$ & 0.33 \\
\hline Dehydration & No & 1 & - \\
\cline { 2 - 4 } & Yes & $0.1(0.01-0.69)$ & $0.05^{\star}$ \\
fever & No & 1 & - \\
\cline { 2 - 4 } & Yes & $24.4(2.42-267.89)$ & $0.02^{\star}$ \\
\hline
\end{tabular}

\section{Discussion}

This study presents an overall prevalence of leptospirosis of $4.7 \%$ among patients who attended renal and general outpatient units of Mulago National Referral Hospital. The current study is one of the first studies to document Leptospirosis among patients with renal disease since previously documented studies in Uganda exclusively targeted apparently healthy populations [11].However, this study addressed a special patient category attending care at a national referral hospital and therefore is not quite comparable to other studies in Uganda. Studies undertaken in Hoima district, in the western part of Uganda revealed a higher prevalence of $35 \%$ of leptospirosis among patients [11]. Other than this, somewhere else in Africa 11 studies carried out among febrile patients attending hospitals had 
prevalence ranging from 2.3-19.8\% which were comparable with the current study [9]. A hospital-based study conducted in Sri Lanka revealed a 15.5\% prevalence of Leptospirosis among febrile patients using an IgM enzyme-linked immunosorbent assay [21]. This test method is more sensitive than the MAT used in the current study. Conversely, ELISA test method results have to be confirmed by MAT to establish the positivity.

This study revealed a number of serovars that were undocumented in the previous study by [11] in Uganda. The current study presents prevalence by serovars as follows; Hebdomadis, Hebdomadis (L.borgapetersenii serovar Nona), Icterohaemorrhagiae (L.interrogans Serovar Icterohaemorrhagiae, Canicola (L. interrogans serovarCanicola), Djasiman (L. interrogansserovarDjasiman), Pomona (L. interrogans serovar Pomona) and Ballum (L. borgpetersenii serovar Kenya). These serovars are known to be pathogenic and associated with Weil's syndrome, hemorrhagic syndrome and acute renal failure that have severe consequences including death $[22,23,8]$. The study by [11] presented a number of limitations ranging from missing serovars in the test panel, cross-reactivity and some failed to grow which were unlikely in the current study.

Patients who reported with signs of abdominal pain were 24.4 times more likely to be diagnosed with Leptospirosis. In a similar hospital-based study, a case report of a 23-year-old male admitted in Hawaii USA with acute abdominal pain. The differential diagnoses for Leptospirosis include cholangitis, pancreatitis, leptospirosis, dengue, typhoid fever among others [24]. Dehydration was a significant variable associated with not having a diagnosis of Leptospirosis. Patients attending the renal and general outpatient unit with signs of dehydration were less likely to be diagnosed with leptospirosis. However other studies report contrary results due to the fact that leptospirosis infection is associated with fever and vomiting which may cause dehydration [25]. Therefore, this less likelihood of dehydration being a factor for Leptospirosis could be that the observed dehydration was caused by other pathogens or factors other than the study's outcome of interest. Additionally, $51.6 \%$ of the participants in this study had a fever with average temperatures of $37.3 \pm 1.1^{\circ} \mathrm{C}$. the participants without fever were 1.3 times less likely to be diagnosed with leptospirosis. Males were at a higher risk than the females of contracting leptospirosis infection. Gender dynamics influence the division of labour and affect the leisure patterns resulting in different exposure pathways for Leptospira organisms for both men and women [26]. In some societies, men have a greater occupational risk of contracting Leptospirosis than women especially among farming communities; and sewers and plumbing workers [27]. The record in the hospital shows that clinicians do not diagnose leptospirosis during their normal practice. During the study period; some patients with mild flu-like symptoms were not sent to the laboratory but rather instead treated clinically which would imply potentially missed possible cases of the disease. This could be attributed to the low awareness of leptospirosis and other zoonoses by clinicians [13] despite their high prevalence in the region.

The results from this study are however a snapshot of what would be obtained for a large scale and rigorous study. There is therefore need for a largescale prospective cohort study to understand the dynamics of leptospirosis within human populations in Uganda. 


\section{Declarations}

\section{Author contributions}

R.W. conducted research and wrote up the initial draft of the manuscript. W.W. and L.M. gave technical advise for the study and supported in revision of the manuscript. J.M. supported data analysis and the flow of the study. S.A. supported drafting of the manuscript and its submission to the journal. L.M. provided laboratory requirements for sample collection and analysis in this study.

\section{Competing interests}

The authors declare no competing interests

\section{References}

1. Ricardo, T., Bergero, L. C., Bulgarella, E. P. \& Previtali, M. A. Knowledge, attitudes and practices (KAP) regarding leptospirosis among residents of riverside settlements of Santa Fe, Argentina.PLoS Negl Trop Dis. 2018.

2. Fornazari, F., Langoni, H., Marson, P. M., Nóbrega, D. B. \& Teixeira, C. R. Leptospira reservoirs among wildlife in Brazil: Beyond rodents. Acta Trop, 178, 205-212 https://doi.org/10.1016/j.actatropica.2017.11.019 (2018).

3. Levett, P. N. \& Leptospirosis Clin Microbiol Rev, 14, 296-326 https://doi.org/10.1128/CMR.14.2.296326.2001 (2001).

4. Adler, B. de la Peña Moctezuma A. Leptospira and leptospirosis. Vet Microbiol 2010.

5. Vijayachari, P., Sugunan, A. P. \& Shriram, A. N. Leptospirosis: An emerging global public health problem.Journal of Biosciences. 2008.

6. Hyeroba, D., Friant, S., Acon, J., Okwee-Acai, J. \& Goldberg, T. L. Demography and health of "village dogs" in rural Western Uganda.Prev Vet Med. 2017.

7. Wallace, R. M. L. et al. The impact of poverty on dog ownership and access to canine rabies vaccination: Results from a knowledge, attitudes and practices survey, Uganda 2013. Infect Dis Poverty. 2017.

8. Costa, F. et al. Global Morbidity and Mortality of Leptospirosis: A Systematic Review.PLoS Negl Trop Dis. 2015.

9. Allan, K. J. et al. Epidemiology of Leptospirosis in Africa: A Systematic Review of a Neglected Zoonosis and a Paradigm for 'One Health' in Africa. PLoS Negl Trop Dis, 9, 1-25 (2015).

10. Dreyfus, A. et al. Cross-Sectional serological survey for leptospira spp.In beef and dairy cattle in two districts in Uganda.Int J Environ Res Public Health. 2017. 
11. Dreyfus, A. et al. Leptstern Ugandaospira Seroprevalence and Risk Factors in Health Centre Patients in Hoima District, We.PLoS Negl Trop Dis. 2016.

12. Croda, J. et al. Leptospirosis pulmonary haemorrhage syndrome is associated with linear deposition of immunoglobulin and complement on the alveolar surface.Clin Microbiol Infect. 2010.

13. Zhang, H. L. et al. Mixed Methods Survey of Zoonotic Disease Awareness and Practice among Animal and Human Healthcare Providers in Moshi, Tanzania. PLoS Negl Trop Dis, 10, e0004476 https://doi.org/10.1371/journal.pntd.0004476 (2016).

14. Clare, C. et al. Guidelines and mindlines: why do clinical staff over-diagnose malaria in Tanzania? A qualitative study.Malar J. 2008.

15. Chipwaza, B. et al. Community Knowledge and Attitudes and Health Workers' Practices regarding Non-malaria Febrile Illnesses in Eastern Tanzania.PLoS Negl Trop Dis. 2014.

16. Crump, J. et al. Etiology of severe non-malaria febrile illness in Northern Tanzania: a prospective cohort study.PLoS Negl Trop Dis. 2013;7.

17. Kyabayinze, D. J. et al. Use of RDTs to improve malaria diagnosis and fever case management at primary health care facilities in Uganda. Malar J, 9, 200 https://doi.org/10.1186/1475-2875-9-200 (2010).

18. Ghai, R. R., Thurber, M. I., El Bakry, A., Chapman, C. A. \& Goldberg, T. L. Multi-method assessment of patients with febrile illness reveals over-diagnosis of malaria in rural Uganda.Malar J. 2016.

19. Araujo, E. R. et al. Acute kidney injury in human leptospirosis: An immunohistochemical study with pathophysiological correlation.Virchows Arch. 2010.

20. Yang, C. W., Wu, M. S. \& Pan, M. J. Leptospirosis renal disease.Nephrol Dial Transplant. 2001.

21. Levett, P. N., Branch, S. L., Whittington, C. U., Edwards, C. N. \& Paxton, H. Two Methods for Rapid Serological Diagnosis of Acute Leptospirosis.Clin Vaccine Immunol. 2002.

22. Forbes, A. E., Zochowski, W. J., Dubrey, S. W. \& Sivaprakasam, V. Leptospirosis and weil's disease in the UK.QJM. 2012.

23. Desakorn, V. et al. Accuracy of a commercial IgM ELISA for the diagnosis of human leptospirosis in Thailand.Am J Trop Med Hyg. 2012.

24. Mazhar, M., Kao, J. J. \& Bolger, D. T. Jr. A 23-year-old Man with Leptospirosis and Acute Abdominal Pain.Hawaii J Med Public Health. 2016.

25. Jauréfuiberry, S. et al. Clinical presentation of leptospirosis: A retrospective study of 34 patients admitted to a single institution in metropolitan France.Clin Microbiol Infect. 2005.

26. Paige, S. B., Malavé, C., Mbabazi, E., Mayer, J. \& Goldberg, T. L. Uncovering zoonoses awareness in an emerging disease "hotspot."Soc Sci Med. 2015.

27. Katz, A. R., Ansdell, V. E., Effler, P. V., Middleton, C. R. \& Sasaki, D. M. Leptospirosis in Hawaii, 19741998: Epidemiologic analysis of 353 laboratory-confirmed cases.Am J Trop Med Hyg. 2002.

\section{Figures}




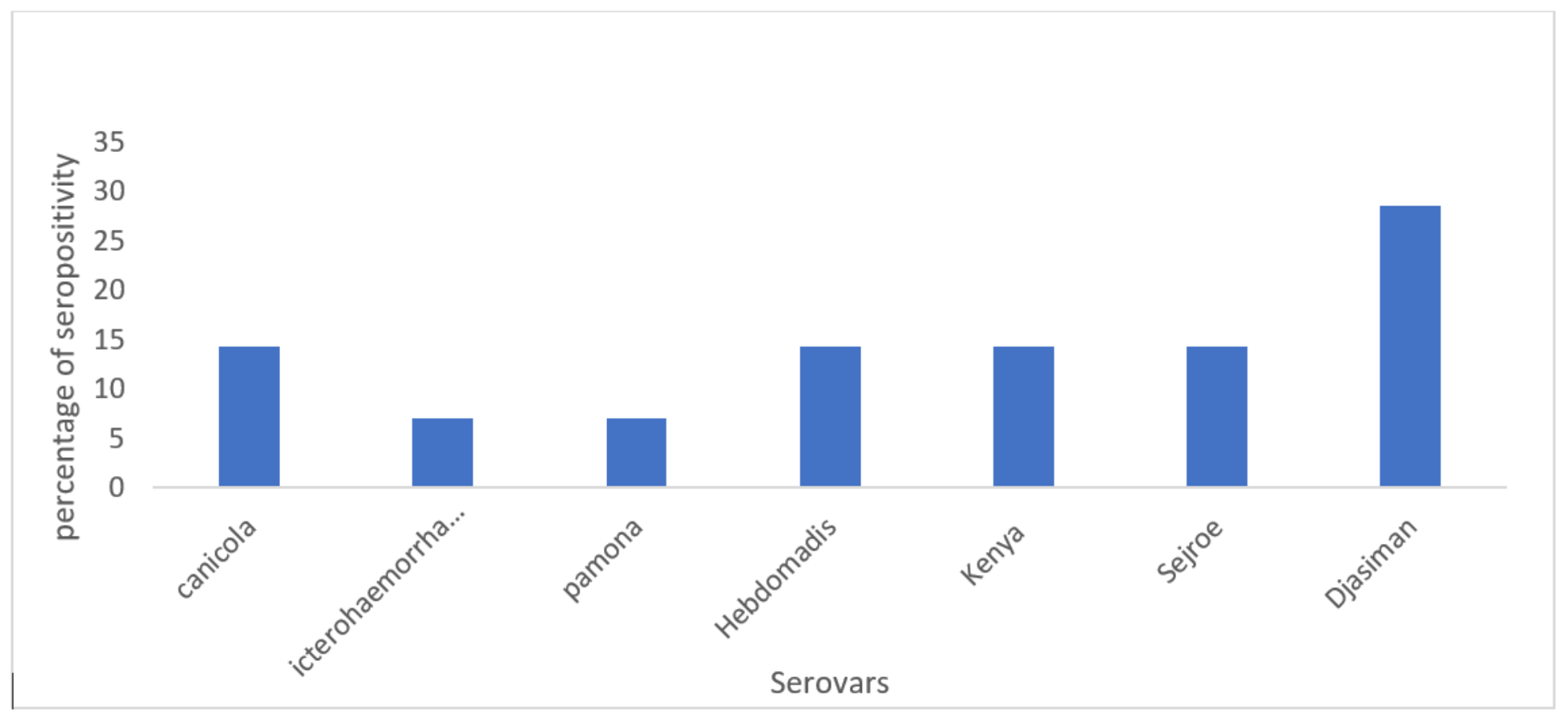

Figure 1

Prevalence of leptospira serovars

\section{Supplementary Files}

This is a list of supplementary files associated with this preprint. Click to download.

- Appendix1Questionnaire.docx

- AppendixiiLaboratoryrequestform.jpg

- lepto.dataset.csv 